\title{
THE ACCURACY OF DIRECT DETERMINATIONS OF OXYGEN AND CARBON DIOXIDE TENSIONS IN HUMAN BLOOD \\ IN VITRO ${ }^{1}$
}

\author{
BY GILES F. FILLEY, ESTHER GAY, AND GEORGE W. WRIGHT \\ (From the Department of Physiology, the Edzuard L. Trudeau Foundation, Saranac Lake, \\ New York)
}

(Submitted for publication November 16, 1953; accepted December 2, 1953)

The need for an accurate yet clinically practical means of determining the tensions of the respiratory gases in human blood has been recognized since Krogh (1) perfected equilibration techniques for in vivo ${ }^{2}$ studies on experimental animals. Several methods (2-7) based on Krogh's principles have been used for analyzing human blood in vitro but as has been pointed out (6) such methods are "fraught with numerous potential sources of error." Indirect estimations of the partial pressure of oxygen in human blood from the hemoglobin dissociation curve can be subject to large (usually random) errors $(2,4)$ and calculation of the carbon dioxide tension of blood depends upon measurement of the plasma $\mathrm{CO}_{2}$ content and $\mathrm{pH}$ by methods that are not as reliable or convenient as one might desire.

The development by Riley, Proemmel, and Franke (5) of a rapid direct technique for determining arterial blood gas tensions in man permits approximately in vivo conditions to be maintained without sacrificing clinical utility. The principle of the method depends upon the equilibration of a gas bubble at atmospheric pressure with blood at $37^{\circ} \mathrm{C}$. in the barrel of a Roughton-Scholander (R-S) syringe and the subsequent analysis of the gas bubble in the capillary portion of the same syringe. Riley evaluated the precision of his method by comparing the tensions of oxygen and carbon dioxide in the blood and gas phase of tonometers equilibrated at $37^{\circ} \mathrm{C}$. The mean of the difference for both gases between the tensions in the two phases was 2 to $3 \mathrm{~mm}$. Hg necessitating the use of correction factors. These correction factors

\footnotetext{
1 These studies were aided by a contract between the Office of Naval Research, Department of the Navy and the Trudeau Foundation (NR 112-214).

2 In Krogh's method flowing blood enters the equilibration chamber at $37^{\circ} \mathrm{C}$. within a few seconds after it leaves the artery.
}

have required revision over a period of several years (6) and vary depending upon the analyst.

We have introduced modifications of the Riley technique which have led to increased precision and clinical applicability.

\section{METHODS OF STUDY}

Two independent approaches for assessing the accuracy of directly determined blood oxygen and carbon dioxide tensions were used. In the first (Table I), human venous blood was equilibrated at $37.2^{\circ} \mathrm{C}$. for one hour in a tonometer containing mixtures of oxygen, carbon dioxide, and nitrogen, the gas phase being analyzed in duplicate on the Haldane apparatus and the blood phase in duplicate by the Riley technique or one of our modifications. The tonometer technique described by Riley, Proemmel, and Franke (5) was used in Series 1. Double-chambered tonometers (8) were used in Series 2 and 3. In the second approach (Table II) each sample of human arterial blood, in addition to being analyzed for $\mathrm{PO}_{2}$ and $\mathrm{PCO}_{2}$ directly, was simultaneously analyzed (9) in duplicate in the Van Slyke apparatus for oxygen and carbon dioxide content within an hour after blood sampling. Duplicate analyses were accepted only if agreement within 0.2 volumes per cent was obtained. Saturation of the blood with oxygen was carried out in the chamber of the Van Slyke apparatus and analysis was performed by the method of Sendroy 8 (10). Plasma $\mathrm{pH}$ was determined by the method of Hastings and Sendroy (11) immediately after blood was drawn. From the hemoglobin dissociation curves of Dill (12) and the nomograms of Van Slyke and Sendroy (13) the blood oxygen and carbon dioxide tensions were calculated. In this manner one can compare the tensions obtained by direct and indirect measurement in the same blood sample.

In each of these two approaches, blood gas tensions were determined directly by the Riley technique or by one of our modifications. In the first series of measurements (Series 1, Table I) blood was analyzed for oxygen

${ }^{8}$ Modified only to the following extent: Instead of using $0.3 \mathrm{cc}$. of 23 per cent ferricyanide reagent, we use 1.0 cc. of a 1.8 per cent ferricyanide reagent. Instead of 2.5 cc. of saline to wash in the $0.5 \mathrm{cc}$. of blood, only $2.0 \mathrm{cc}$. is used so that the final volume of liquid in the Van Slyke chamber before gas absorption is $3.5 \mathrm{cc}$. 
TABLE I

Oxygen and carbon dioxide tensions of the blood (human) and gas phases of tonometers equilibrated for 1 hour at $37.2^{\circ} \mathrm{C}$.

\begin{tabular}{|c|c|c|c|c|}
\hline \multirow[b]{2}{*}{$\mathrm{P}_{2}(m m . H g)$} & \multirow{2}{*}{$\begin{array}{c}\text { Data } \nmid \text { of Riley, } \\
\text { Proemmel, and } \\
\text { Franke }\end{array}$} & \multicolumn{3}{|c|}{ Data of this study } \\
\hline & & Series 1 & Series 2 & Series 3 \\
\hline $\begin{array}{l}\text { Number of determinations } \\
\text { Range of oxygen tensions } \\
\text { Mean } \mathrm{PO}_{2} \text { in blood } \\
\text { Mean } \mathrm{PO}_{2} \text { of tonometer gas } \\
\text { Difference of the means } \\
\text { S.D. of this difference } \\
\text { Mean of the differences* } \\
\text { Extreme differences (blood minus gas) }\end{array}$ & $\begin{array}{c}18 \\
22-111 \\
66.7 \\
63.4 \\
+3.3 \\
\pm 2.15 \\
3.3 \\
0 \text { to }+8\end{array}$ & $\begin{array}{c}37 \\
52-113 \\
81.9 \\
78.7 \\
+3.2 \\
\pm 3.72 \\
4.3 \\
-2 \text { to }+15\end{array}$ & $\begin{array}{c}15 \\
52-103 \\
78.8 \\
77.6 \\
+1.2 \\
\pm 3.09 \\
2.8 \\
-6 \text { to }+6\end{array}$ & $\begin{array}{c}19 \\
46-88 \\
70.8 \\
70.5 \\
+0.3 \\
\pm 1.75 \\
1.4 \\
-2 \text { to }+3\end{array}$ \\
\hline \multicolumn{5}{|l|}{$\mathrm{PcO}_{2}(\mathrm{~mm} . \mathrm{Hg})$} \\
\hline $\begin{array}{l}\text { Number of determinations } \\
\text { Range of carbon dioxide tensions } \\
\text { Mean } \mathrm{PCO}_{2} \text { in blood } \\
\text { Mean } \mathrm{PCO}_{2} \text { of tonometer gas } \\
\text { Difference of the means } \\
\text { S.D. of this difference } \\
\text { Mean of the differences* } \\
\text { Extreme differences (blood minus gas) }\end{array}$ & $\begin{array}{l}21 \\
27-50 \\
36.3 \\
38.6 \\
-2.3 \\
\pm 2.05 \\
2.5 \\
-8 \text { to }+2\end{array}$ & $\begin{array}{c}37 \\
26-94 \\
37.5 \\
41.7 \\
-4.2 \\
\pm 2.75 \\
4.4 \\
-16 \text { to }+2\end{array}$ & $\begin{array}{c}15 \\
36-50 \\
37.8 \\
43.5 \\
-5.7 \\
\pm 2.79 \\
6.0 \\
-10 \text { to }+2\end{array}$ & $\begin{array}{c}19 \\
23-49 \\
39.3 \\
41.5 \\
-2.2 \\
\pm 2.17 \\
2.4 \\
-6 \text { to }+1\end{array}$ \\
\hline
\end{tabular}

* Without regard to sign.

† In Table I of Riley, Proemmel, and Franke's paper (5) one carbon dioxide and four oxygen determinations were not used in the calculation of average differences. These five determinations are also omitted from his data shown in the present table.

and carbon dioxide tension by the original Riley method (5) except for minor changes in technique.4 In the second series the procedure was identical with that of the first series except that a microscope reading device was used to measure the length of the bubble in the RoughtonScholander syringe. In Series 3 a change in the technique for absorbing gases from the bubble was introduced to minimize the drainage error of the original Riley technique; the microscope was employed as in Series 2. In all three series the tension determinations were carried out in duplicate, checks within less than $6 \mathrm{~mm}$. $\mathrm{Hg}$ being required both for $\mathrm{PO}_{2}$ and $\mathrm{PCO}_{2}$. Tensions were expressed as the average of duplicate determinations. All tension determinations were performed immediately after the blood was obtained, the equilibration period being completed within 9 minutes after blood-sampling.

\section{NEW TECHNICAL PROCEDURES}

Microscope reading device. In the original Riley method (5) the bubble length was estimated by the unaided eye to 0.1 unit in the R-S capillary. While an experienced

4 Instead of a 7 -minute equilibration period at $37^{\circ}$ C. a 6 -minute period at $37.2^{\circ} \mathrm{C} .\left( \pm 0.1^{\circ} \mathrm{C}\right.$.) was used; a 25 $\mathrm{R}-\mathrm{S}$ unit bubble was introduced in all instances; the heparin-sodium fluoride solution was made up by adding $75 \mathrm{mg}$. of $\mathrm{NaF}$ to each cc. of Heparin (Lederle) containing $10 \mathrm{mg}$. heparin per cc.; and a 10 per cent commercial detergent solution ("Dreft" was found to be satisfactory) was used instead of saline to wash the capillary of the R-S syringe before the introduction of $1 \mathrm{~N} \cdot \mathrm{NaOH}$. analyst is able to make this interpolation with a consistent and small error, the reading error may be large and variable in inexperienced hands. The device shown in Fig-

TABLE II

Oxygen and carbon dioxide tensions of human arterial blood determined simultaneously by a direct and indirect method

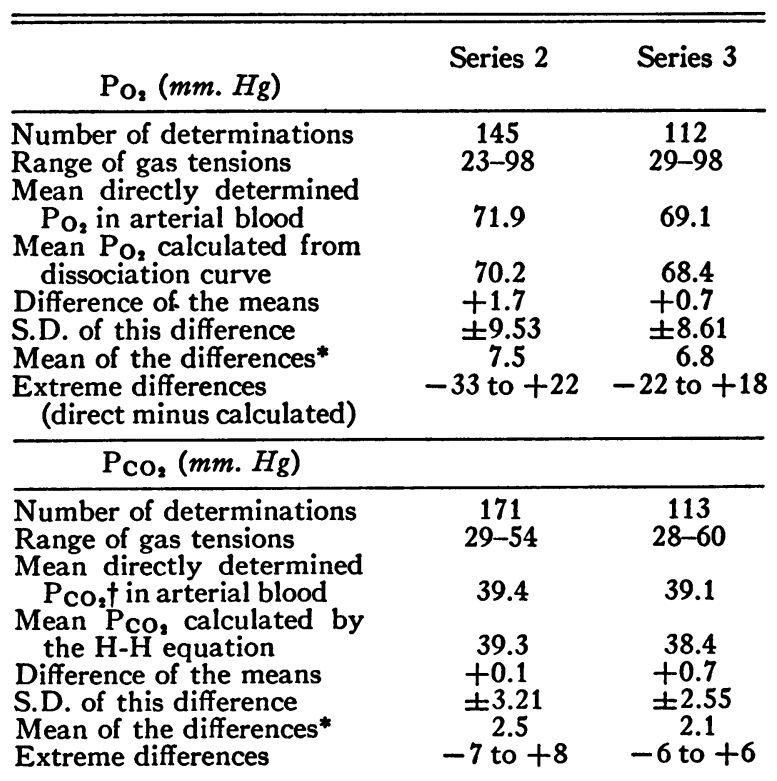

* Without regard to sign.

† Corrected on the basis of tonometer studies (see Text). 


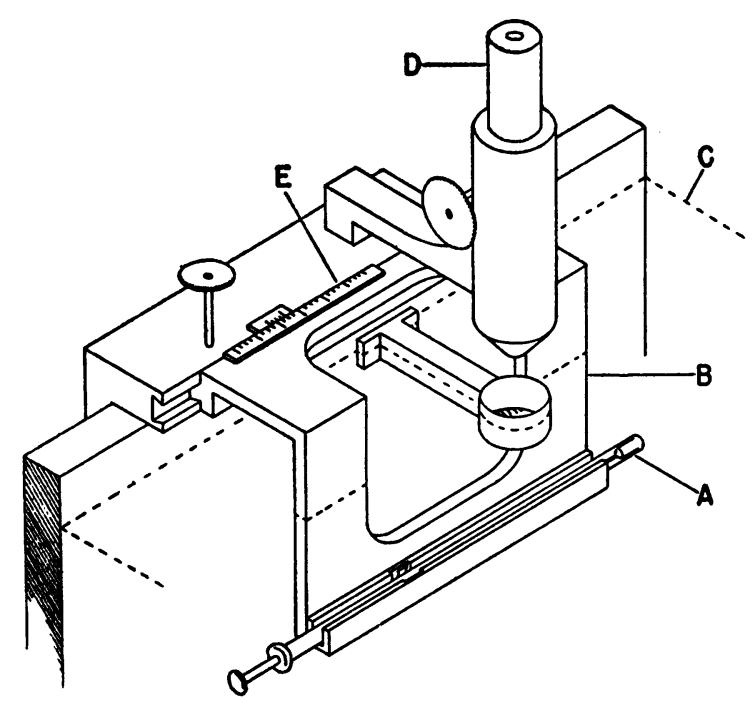

FIG. 1.

The R-S syringe, A., rests in the sliding carriage, B., $20 \mathrm{~mm}$. below the water level, C., in the constant temperature bath. The menisci of the bubble in the R-S capillary can be brought to a hair-line in the eye-piece of the microscope, D., and the distance between them measured to the nearest $0.1 \mathrm{~mm}$. along the scale, E., by means of the vernier adjustment. ure 1 (used in both Series 2 and 3) permits visualization at $5 \times$ magnification of the entire capillary portion of the $\mathrm{R}-\mathrm{S}$ syringe and eliminates parallax. By means of the sliding carriage and vernier adjustment ${ }^{5}$ the bubble length may be determined directly to the nearest $0.1 \mathrm{~mm}$. The error in partial pressure which results from measurements with the microscope and vernier can be calculated to be less than $1 \mathrm{~mm}$. $\mathrm{Hg}$ both for oxygen and carbon dioxide.

Absorption of gases in the cup of the $R-S$ syringe. The following procedure (used only in Series 3) was adopted to avoid the introduction of viscous alkaline reagents into the mid-portion of the capillary where the bubble length is measured. This maneuver was devised in an attempt to lessen the error caused by uneven drainage of the capillary wall.

After the bubble has been introduced into the R-S syringe and equilibrated at $37.2^{\circ} \mathrm{C}$. for 6 minutes, the mercury and most of the blood are ejected under water and the bubble pushed into the capillary as described in the original Riley method (5). Following the reading of the initial bubble length, the syringe is removed from the bath and held vertically with the cup-end up while the bubble is advanced till the distal end is about $8 \mathrm{~mm}$. from the cup (Figure 2a). The cup is then emptied of blood by aspiration and wiped clean with a toothpick swab. It is then

5 Part of a conventional graduated mechanical stage.

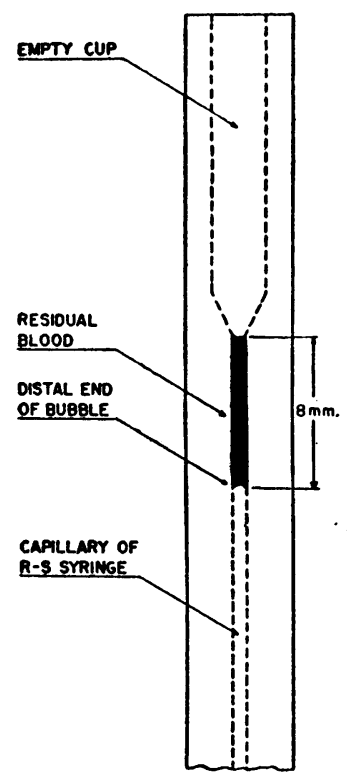

a.

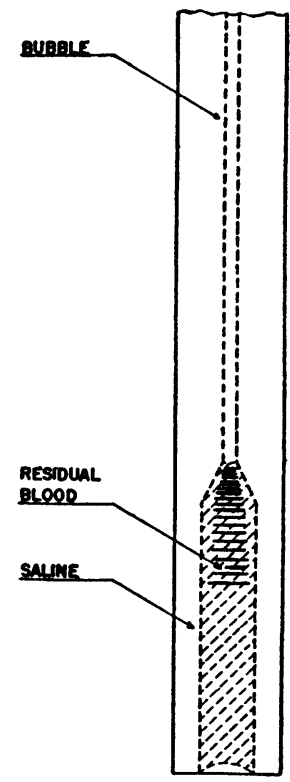

b.

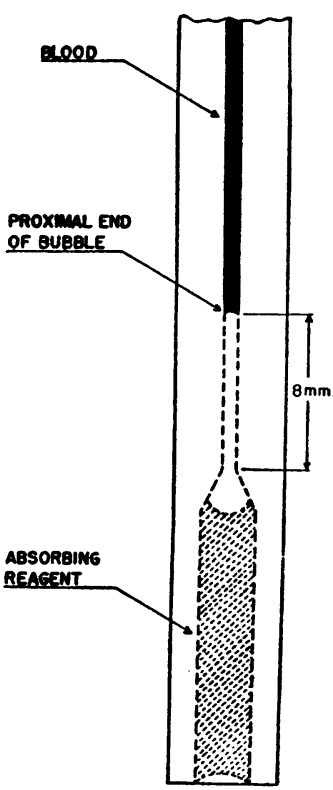

c.

Fig. 2. Positions of the Roughton-Scholander Syringe during Three Stages of Bubble Manipulation and Analysis

In $a$, the syringe is held upright after the cup has been emptied of blood with a "waste" syringe and wiped clean; it is then filled with saline and inverted, $b$, the residual blood being expelled into the saline. The inverted position allows manipulation and absorption of the bubble to be carried out without losing the bubble. In $c$, gas absorption is accomplished without intimate contact between blood and alkaline reagents. 
filled with physiological saline, the syringe inverted, and the residual blood at the distal end of the bubble expelled into the saline-filled cup by advancing the bubble until it reaches the end of the capillary (Figure $2 \mathrm{~b}$ ). The bubble is then withdrawn into the capillary again so that the distal end of the bubble is $8 \mathrm{~mm}$. from the cup which is then emptied and refilled with $2 \mathrm{~N} \mathrm{KOH} .^{6}$

Absorption of $\mathrm{CO}_{2}$ is carried out with the syringe held cup-end down by advancing the bubble so that it protrudes into the alkali until the proximal end is $8 \mathrm{~mm}$. from the cup (Figure 2c), allowing it to remain there for about 1 second, withdrawing it and repeating this procedure five times. The $\mathrm{KOH}$ in the cup is then replaced with saline while the distal end of the bubble is $8 \mathrm{~mm}$. from the cup. The bubble is next pulled back followed by saline to the mid-portion of the capillary for the second reading. The proximal end of the bubble is now bathed in blood, the distal end in saline containing a small amount of $\mathrm{KOH}$.

Absorption of $\mathrm{O}_{2}$ is carried out as for $\mathrm{CO}_{2}$, the bubble being again protruded into the cup which has been filled with alkaline hyposulfite solution (5) ; advance and retraction of the bubble is repeated five times; on the last time the protruded bubble and the hyposulfite are allowed about 4 seconds of contact. After the hyposulfite has been washed out with saline (distal end of bubble $8 \mathrm{~mm}$. from the cup), the bubble followed by saline is again drawn into the capillary for the final reading.

During the manipulation of the bubble from capillary to cup and back, the syringe must be held with the cup pointed downward in order to avoid losing the bubble. The use of detergents is not necessary. A $25 \mathrm{R}-\mathrm{S}$ unit bubble is introduced in all instances. Duplicate analyses can be completed within 30 minutes after blood is sampled.

\section{RESULTS}

As shown in Table I we have confirmed the observation of Riley, Proemmel, and Franke (5) that on the average the determined $\mathrm{Po}_{2}$ was higher and the $\mathrm{PCO}_{2}$ lower in the blood than in the gas phase of the tonometer. When the microscope reading device was used (Series 2) the difference of the means was reduced for oxygen and increased for carbon dioxide. Measurements made with gas absorption being performed in the cup (Series 3) showed a further reduction in the difference for oxygen to $0.3 \mathrm{~mm}$. Hg. With this modification the difference of the means for $\mathrm{CO}_{2}$ was $2.2 \mathrm{~mm}$. $\mathrm{Hg}$.

In our hands measurement by the original method of Riley, Proemmel, and Franke (Series 1) produced greater variability in the differences between the tensions of the blood and gas phase of the tonometer than he reported (5). The use of the microscope device in carrying out the determi-

( The surface tension of $\mathrm{KOH}$ is less than that of $\mathrm{NaOH}$. The solubility of oxygen is less in $2 \mathrm{~N}$ than in $1 \mathrm{~N} \mathrm{KOH}$. nations of Series 2 did not significantly ${ }^{7}$ diminish the variability as shown in Series 1, in which readings were made by a single experienced technician (E. G.) with the unaided eye. However, the modification of absorbing gases in the cup in Series 3 reduced the standard deviation of the difference of the means to $1.75 \mathrm{~mm}$. $\mathrm{Hg}$ for oxygen and 2.17 $\mathrm{mm}$. $\mathrm{Hg}$ for carbon dioxide.

In Table II are shown the directly determined tensions (corrected on the basis of the tonometer studies of Series 2 and 3) as compared with the tensions determined indirectly from the standard hemoglobin dissociation curve and the HendersonHasselbach equation. Using the Riley technique modified by the use of the microscope and vernier (Series 2, Table II), we found that the mean oxygen tension was $1.7 \mathrm{~mm}$. $\mathrm{Hg}$ higher than that calculated from the hemoglobin dissociation curve and that the individual differences between the two values varied widely; the mean direct and calculated values for $\mathrm{PCO}_{2}$ agreed more closely and there was less scatter in the individual differences. The modification of absorbing gases in the cup of the R-S syringe (Series 3 ) resulted in less than a millimeter of $\mathrm{Hg}$ difference between the means of the direct and calculated blood tensions and the variability of the differences was also reduced.

In all three series of direct tension determinations the mean of the difference between duplicates was $2 \mathrm{~mm}$. $\mathrm{Hg}$ with a standard deviation of \pm 1.5 $\mathrm{mm} . \mathrm{Hg}$.

\section{DISCUSSION}

The major sources of error in micro-tonometric techniques for determining blood gas tensions were pointed out by Krogh (14) who emphasized the importance of exact readings of the bubble length, scrupulous cleanliness of the capillary and avoidance of any distortion of the menisci at the ends of the gas bubble. The microscopic device described in the present report, although not greatly affecting the precision of the Riley method as carried out by us, has two advantages. In the first place, it reduces dependence on technical skill by shortening the training period required for an analyst to develop a consistent reading error. Secondly, the device permits visualization of the

7 Although the S.D. of the difference of the means for oxygen in Series 1 and 2 differ by $0.63 \mathrm{~mm}$. $\mathrm{Hg}$, the standard error of this difference is $0.71 \mathrm{~mm}$. $\mathrm{Hg}$. 
entire capillary bore and the fluid layer surrounding the bubble at a magnification of 5 diameters.

Uneven drainage of both blood and absorbing reagents was observed by means of the microscope when the technique used by Riley, Proemmel, and Franke (5) for absorbing gases was employed. Inspection of the bubble indicates that the increased precision obtained by carrying out gas absorption in the cup of the R-S syringe can be attributed largely to improved drainage. This technique also probably reduces errors caused by transfer of $\mathrm{O}_{2}$ between the bubble and the $\mathrm{CO}_{2}$-absorber and the transfer of $\mathrm{O}_{2}$ and $\mathrm{CO}_{2}$ between the bubble and the saline solution since no concentrated reagents are drawn into the mid-portion of the capillary (14).

The oxygen tension of human blood analyzed by the combined modifications (Table I, Series 3 ) averaged only $0.3 \mathrm{~mm}$. $\mathrm{Hg}$ higher than the $\mathrm{Po}_{2}$ in gas to which the blood had been exposed for 1 hour at $37.2^{\circ} \mathrm{C}$. in a tonometer. The directly determined $\mathrm{PCO}_{2}$ of such blood, however, averaged $2.2 \mathrm{~mm}$. $\mathrm{Hg}$ lower than the carbon dioxide tension in the gas phase. It is unlikely that this latter difference, almost identical with that found by Riley, Proemmel, and Franke (5), was caused by faulty tonometric technique, since we have used doublechambered tonometers (8) which allow separation of the blood and gas phases after equilibration without change in the temperature or the total pressure of the system. The difference was reasonably consistent (S.D. of the difference $\pm 2.17 \mathrm{~mm}$. $\mathrm{Hg}$ ) and probably represents a constant error of the method.

These tonometer studies suggest that when the combined modifications described herein are used, no correction factor is needed for $\mathrm{Po}_{2}$ but that a correction factor, based on such studies, is required for $\mathrm{PCO}_{2}$. Another justification for the use of this correction is evident in Table II in which corrected direct carbon dioxide tensions of human arterial blood agree closely with the values obtained by calculation from the $\mathrm{CO}_{2}$ content and plasma $\mathrm{pH}$ determined on the same blood samples.

It has been suggested by Roos and Black (7) that an appreciable error in the measurement of blood $\mathrm{Po}_{2}$ will result whenever a bubble of gas at atmospheric pressure is introduced into blood the total gas tension of which is significantly subatmospheric. It can be shown, however, that so long as the initial bubble $\mathrm{PO}_{2}$ is equal to or lower than that of the blood phase and the blood $\mathrm{Po}_{2}$ is less than $90 \mathrm{~mm} . \mathrm{Hg}$, the shape of the hemoglobin dissociation curve and the low solubility of nitrogen will prevent a significant increase of the bubble $\mathrm{Po}_{2}$ consequent to $\mathrm{N}_{2}$ transfer during the equilibration period. In fact, as has been pointed out by Riley, Proemmel, and Franke (5), whenever the $\mathrm{PO}_{2}$ of the blood is low, the combiningpower of hemoglobin for $\mathrm{O}_{2}$ will permit one to use an initially higher bubble $\mathrm{Po}_{2}$ without serious error after equilibration.

For many clinical studies at sea-level, even though the total gas tension of the arterial blood in both normal subjects and in patients is probably subatmospheric by 1 to 3 per cent of an atmosphere $(15,16)$, the equilibration of such blood with a gas bubble of normal "alveolar air" at atmospheric pressure can be calculated to involve less than 1 $\mathrm{mm}$. $\mathrm{Hg}$ change in oxygen tension. Evidence for the validity of such calculations is shown in Table II, Series 3, which summarizes the oxygen data obtained from the arterial blood of clinical subjects in the $\mathrm{Po}_{2}$ range of 29 to $98 \mathrm{~mm}$. $\mathrm{Hg}$. The variation observed in the individual differences between the directly determined oxygen tension and that calculated from the dissociation curve is the result primarily of random errors in the manometric determination of oxygen content and capacity. Since the averages of 112 simultaneous determinations of $\mathrm{PO}_{2}$ by direct and indirect methods agree closely, there is no large constant error in the present technique of equilibrating arterial blood with gas at atmospheric pressure.

The precision obtained by the present method compares favorably with the results achieved by the painstaking work of Lambertsen and Bunce (6) who used considerably different equipment. In Table III the results of our tonometer studies using the combined modifications (Series 3) are analyzed with respect to the differences (without regard to sign) between the tensions obtained in single blood determinations and the tensions in the gas phase of the tonometer. The mean of the differences for $\mathrm{PO}_{2}$ and the variability of these differences were approximately the same in the two methods. The mean of the differences was greater for $\mathrm{PCO}_{2}$ determined by our method than was the mean of the differences reported by Lambertsen and Bunce but the consistency of the individual 
TABLE III

Comparison of the results of the present tonometer studies of Series 3 and the data of Lambertsen and Bunce (6) as regards individual differences between the tensions of the blood and gas phase in single determinations without regard to sign

\begin{tabular}{|c|c|c|c|c|c|c|c|}
\hline & \multicolumn{2}{|c|}{$\begin{array}{c}\text { Range of gas } \\
\text { tensions } \\
m m . H g\end{array}$} & \multirow{2}{*}{$\begin{array}{l}\text { Number of } \\
\text { analyses }\end{array}$} & \multicolumn{2}{|c|}{$\begin{array}{l}\text { Mean of the } \\
\text { individual } \\
\text { differences } \\
m m . H g\end{array}$} & \multicolumn{2}{|c|}{$\begin{array}{c}\text { Standard deviation } \\
\text { of the mean of the } \\
\text { individual differences } \\
\text { mm. } \mathrm{Hg}\end{array}$} \\
\hline & $\mathrm{Po}_{2}$ & $\mathrm{PCO}_{2}$ & & $\mathrm{Po}_{2}$ & $\mathrm{PcO}_{2}$ & $\mathrm{PO}_{2}$ & $\mathrm{PCO}_{2}$ \\
\hline Data of Lambertsen and Bunce & $\begin{array}{l}64-74 \\
97-98\end{array}$ & $\begin{array}{l}50-62 \\
37-39\end{array}$ & $\begin{array}{l}16 \\
13\end{array}$ & $\begin{array}{l}1.7 \\
1.3\end{array}$ & $\begin{array}{l}1.5 \\
1.7\end{array}$ & $\begin{array}{l} \pm 2.1 \\
\pm 1.2\end{array}$ & $\begin{array}{l} \pm 1.8 \\
\pm 2.1\end{array}$ \\
\hline Our data of Series 3 & $45-90$ & $23-49$ & 38 & 1.66 & 2.82 & \pm 1.31 & \pm 1.93 \\
\hline
\end{tabular}

$\mathrm{PCO}_{2}$ differences is entirely comparable. When a correction factor of $+2 \mathrm{~mm}$. $\mathrm{Hg}$ is applied to our $\mathrm{CO}_{2}$ tension determinations, the precision of the two methods becomes virtually identical.

It is questionable whether or not the use of any in vitro technique can give arterial blood gas tension values identical to those existing in the blood in vivo. Evidence on the time rate of decline of oxygen tension in shed human arterial blood treated with sodium fluoride is conflicting (5-7, 17) but may be of the order of $0.3 \mathrm{~mm}$. $\mathrm{Hg}$ per minute at $37^{\circ} \mathrm{C}$. during the first hour after blood is sampled. The present method requires $9 \mathrm{~min}$ utes for the completion of the blood-gas equilibrium after blood sampling (a slightly shorter period than that needed in Lambertsen's technique [18]). Unless there is a very rapid change in gas tensions of shed blood during the first few minutes (Krogh [17] could demonstrate none at all in rabbit blood during the first minute), the oxygen tension determined in vitro by our modification of Riley's method is within a few millimeters of the tension in vivo.

\section{SUMMARY}

1. The accuracy of the original Riley bubble method for the direct determination of blood gas tensions in man has been examined by tonometer studies.

2. Two modifications of the method have reduced dependence on technical skill and have led to greater precision.

3. After these modifications were instituted the difference between the means of actual blood gas tensions (tonometer values) and determined tensions was $0.3 \mathrm{~mm}$. $\mathrm{Hg}$ (S.D. \pm 1.75 ) for oxygen and $2.2 \mathrm{~mm}$. Hg (S.D. \pm 2.17 ) for carbon dioxide.
4. With the present modified technique the difference between the mean gas tensions of human arterial blood calculated from the hemoglobin dissociation curve and the Henderson-Hasselbach equation and the gas tensions determined directly was $0.7 \mathrm{~mm}$. $\mathrm{Hg}$ (S.D. \pm 8.61 ) for oxygen and $0.7 \mathrm{~mm}$. $\mathrm{Hg}$ (S.D. \pm 2.55 ) for carbon dioxide.

\section{ACKNOWLEDGMENT}

We wish to acknowledge the technical assistance of Dorothy Proemmel, Leroy Grinnell, and Frederick Mader, Jr.

\section{REFERENCES}

1. Krogh, A., Some new methods for the tonometric determination of gas-tensions in fluids. Skand. Arch. f. Physiol., 1908, 20, 259.

2. Barcroft, J., and Nagahashi, M., The direct measurement of the partial pressure of oxygen in human blood. J. Physiol., 1921, 55, 339.

3. Hick, F. K., Partial pressure of oxygen in arterial blood of patients: description of an aerotonometer method. Proc. Soc. Exper. Biol. \& Med., 1936, 33, 582.

4. Comroe, J. H., Jr., and Dripps, R. D., Jr., The oxygen tension of arterial blood and alveolar air in normal human subjects. Am. J. Physiol., 1944, 142, 700.

5. Riley, R. L., Proemmel, D. D., and Franke, R. E., A direct method for determination of oxygen and carbon dioxide tensions in blood. J. Biol. Chem., $1945,161,621$.

6. Lambertsen, C. J., and Bunce, P. L., Modification of Riley's method in Methods in Medical Research, Chicago, Ill., The Yearbook Publishers, 1950, vol. II, p. 165.

7. Roos, A., and Black, H., Direct determination of partial and total tensions of respiratory gases in blood. Am. J. Physiol., 1950, 160, 163.

8. Austin, J. H., Cullen, G. E., Hastings, A. B., McLean, F. C., Peters, J. P., and Van Slyke, D. D., Studies 
of gas and electrolyte equilibria in blood. I. Technique for collection and analysis of blood, and for its saturation with gas mixtures of known composition. J. Biol. Chem., 1922, 54, 121.

9. Van Slyke, D. D., and Neill, J. M., The determination of gases in blood and other solutions by vacuum extraction and manometric measurement. J. Biol. Chem., 1924, 61, 523.

10. Sendroy, J., Jr., Manometric determination of hemoglobin by the oxygen capacity method. J. Biol. Chem., 1931, 91, 307.

11. Hastings, A. B., and Sendroy, J., Jr., Studies of acidosis. XX. The colorimetric determination of the blood $\mathrm{pH}$ at body temperature without buffer standards. J. Biol. Chem., 1924, 61, 695.

12. Handbook of Respiratory Data in Aviation, Committee on Medical Research, Office of Scientific Re- search and Development, National Research Council, Washington, D. C., 1944.

13. Van Slyke, D. D., and Sendroy, J., Jr., Studies of gas and electrolyte equilibria in blood. XV. Line charts for graphic calculations by the HendersonHasselbalch equation, and for calculating plasma carbon dioxide content from whole blood content. J. Biol. Chem., 1928, 79, 781.

14. Krogh, A., On microanalysis of gases. Skand. Arch. f. Physiol., 1908, 20, 279.

15. Krogh, A., and Krogh, M., On the tensions of gases in the arterial blood. Skand. Arch. f. Physiol., 1910, 23, 179.

16. Branscomb, B. V., Unpublished data from this laboratory.

17. Krogh, A., On the oxygen-metabolism of the blood. Skand. Arch. f. Physiol., 1910, 23, 193.

18. Lambertsen, C. J., Personal communication.

\section{SPECIAL NOTICE TO SUBSCRIBERS}

Post Offices will no longer forward the Journal when you move.

Please notify The Journal of Clinical Investigation, Business Office, 622 West 168th Street, New York 32, N. Y. at once when you have a change of address, and do not omit the zone number if there is one. 